Peer-Reviewed Article

ISSN: 2162-3104 Print/ ISSN: 2166-3750 Online

Volume 6, Issue 2 (2016), pp. 415-430

(C) Journal of International Students

http://jistudents.org/

\title{
English Language Learners in Higher Education: An Exploratory Conversation
}

\author{
Jamie Harrison \\ Auburn University (USA) \\ Hong Shi \\ Auburn University (USA)
}

\begin{abstract}
This article discusses an exploratory conversation between a newly hired assistant professor of ESOL Education and one of her graduate level students taking the methods and materials course. The graduate student was an English learner (international student), and therefore offered this new professor an opportunity to explore her practice of working with English learners in a new context outside of $\mathrm{K}-12$ schools. The discussion followed theoretical protocols of cogenerative dialogue in which the student brought in artifacts from the recently completed course that exemplified easy and difficult assignments. Both professor and student were able to examine their own practices in relation to access of curriculum and strategies that encourage that access.
\end{abstract}

Keywords: English language learners, higher education, learning strategies, pedagogy

Study abroad has long been an avenue for college-aged students to experience other cultures and gain real-world experience while receiving an education, and the United States continues to be a 
popular destination for students from around the world. According to the Open Doors 2014 report, enrollment trends of international students in U.S. colleges and universities show continued and steady growth since the 1950s (Institute of International Education, 2014). Current 2013/2014 data indicate an $8.1 \%$ growth over the prior year with $4.2 \%$ of the total U.S. higher education population being international (Institute of International Education, 2014). Students studying at the undergraduate level make up $41 \%$ of the international student population, with graduate level students making up 38\% (Institute of International Education, 2014). Many universities have included recruitment of international students as a high priority in institutional planning, and for-profit pathway programs tied to corporate entities are on the rise in the U.S. (Redden, 2014). With this in mind, understanding the needs of high level adult English language learners (ELLs) in mainstream university settings is paramount to providing appropriate instruction and services.

\section{LITERATURE REVIEW}

While many studies have focused on diverse populations' access to and success in postsecondary institutions (Walpole, 2007), there have been few studies that focus on ELLs in particular (Kanno \& Cromley, 2013). Furthermore, the recent Access to Success initiative, a federal program proposed by administrators of public postsecondary institutions, targeted low-income and minority students with no special emphasis on language minority students in their goal to increase college access and attainment (Engle \& Lynch, 2009).

Few studies have been conducted that focus on the academic experiences of ELLs in higher education. Instead, studies remain centered on the cultural aspects international students encounter in mainstream settings in higher education. Banazzo and Wong (2007) report findings of a study about Japanese international female students' experiences of discrimination, prejudice and stereotype. Another study presents the narrative of one Chinese student's perceptions of invisibility (Hsieh, 2007). Valdez (2015) also invokes the concept of invisibility in her examination of 15 Chinese international students. While also focused on participants' perceptions of how they were viewed by other students and faculty, 
inarguably an important topic, the study did not strictly address classroom pedagogical practices. With the changing demographics of student populations at universities within the U.S., there is a call for more culturally responsive teaching practices. Wang and Machado (2015) argue for more training at writing centers to help address the language acquisition and academic needs of international students. These efforts, as recognized by the authors, are seldom enough (Wang \& Machado, 2015). Lin and Scherz (2005) call for a "paradigm shift for professional practice" (p. 28). More instructor training is needed in culturally responsive practices and students and instructors should be mutually responsible for the learning that takes place in the classroom (Lin \& Scherz, 2005).

Research suggests that success at the postsecondary level is contingent upon target language proficiency which itself is related to many factors (Bifuh-Ambe, 2011). Bifuh-Ambe (2011) notes that ELLs must employ a variety of learning and cognitive strategies; yet little research has been done to identify available resources beyond what writing centers are doing to meet needs for students and faculty (Wang \& Machado, 2015). With limited special assistance available for ELLs once they have entered the mainstream university classroom, these students are challenged by language difficulties, differing academic environmental expectations, and occlusion of background knowledge. Cho and Reich (2008, p. 238) note that in the context of secondary education,

ELLs should have full access to appropriate curricula taught by qualified teachers using appropriate instructional resources and methods that match students' language and grade level. However, not many schools can afford such support (e.g., bilingual instructional materials, time, and specific guidelines).

At the postsecondary level, little attention is given to such services once students meet entry requirements for the institution, and no acknowledgement is made of their language learning status. In a study of factors affecting international students' transition to higher education, Kwon (2009) reveals affective influences such as feelings of isolation, intimidation, homesickness and loneliness on international students in higher education. Marambe, Vermunt, and Boshuizen (2012) suggest that patterns of learning are influenced by 
culture and international students bring with them various approaches to learning that might be in direct contradiction to the environments in which they have immersed themselves for study.

Strategy use in language learning has long been researched (Dornyei \& Scott, 1997; Ehrman, Leaver, \& Oxford, 2003; Oxford, 1989a, 1989b; Rubin, 1975 as cited in Parks \& Raymond, 2004) yet, social context has rarely been considered (Parks \& Raymond, 2004). Furthermore, international student access to and achievement in academic subjects (not the learning of English), has been given even less attention. Buckridge and Guest (2007) discuss the viability of active learning-centered approaches to classrooms in relation to diversity and learner engagement. Following Biggs' (2003, as cited in Buckridge \& Guest, 2007) diagram of actions that move on a spectrum from low to high levels of engagement, their discussion focuses on the responsibilities of both the teacher and the student in a learning situation. Biggs suggests in comments at the end of the discussion that the essential job of the teacher is to provide the greatest degree of freedom for all students in a course, and success in those assignments for various learners will depend upon scaffolds and supports offered (Buckridge \& Guest, 2007).

International students who are also English learners rely on a complex set of personal language and academic learning skills as well as culturally embedded notions of what academic environments look like. Instructors as well rely on established norms for academic content delivery with very little attention given to how that content is received outside of those norms. As international students with a wide variety of English language proficiencies are heavily recruited (Redden, 2014), it is imperative to change the focus of research from the basics of cultural divide to look at the academic experiences of ELLs in higher education. It is no longer enough to understand the cultural nuances of interaction and difference, but faculty and students alike must become cognizant of the academic challenges presented by having ELLs in mainstream university settings, and take appropriate action to mitigate these challenges. This study is an attempt to shed light on the assignments in one course as experienced by one ELL graduate level student and one professor. 


\section{RESEARCH METHOD}

\section{Context for Study}

As a newly hired assistant professor of ESOL Education at a major research university, I expected that my students would be currently practicing teachers working on a master's degree for further certification in the field to teach ESOL in the P-12 environment. However, I was both surprised and delighted to find that I had very high level English learners enrolling in my courses as non-degree seeking students from various other master's and doctoral level programs. Quickly I became aware that I would have to use many of the strategies and best practices associated with teaching ELLs concurrently while teaching about those strategies and best practices. I was immediately interested in the experiences of high level English learners who are mainstreamed into master's and doctoral level courses in the university setting. When one of my students, a Chinese doctoral student in Adult Education, came to me to talk about research in the field of TESOL, it seemed the perfect opportunity to explore our various perspectives on the course I had recently taught (in which she had been a participant). I was curious about her perceptions of the various activities conducted both in and out of class to meet the objectives of the course. It was an opportunity for me to gain information about my teaching practices while exploring the perspectives of non-native English speakers in the university setting.

\section{Theoretical Framework}

The focus of this study was to better understand the experience of one ELL enrolled in a master's level ESOL Education course entitled, "Teaching English to Speakers of Other Languages P12 ," and through understanding this experience, make connections to teaching practice. The conversation took place at the end of the course, so no change was possible to enact during the course, thus protecting the student-researcher. This study was rooted in phenomenological theory (Moustakas, 1994; Patton, 1990) which focuses on individuals making meaning via examination of lived experiences. The participants utilized co-generative dialogue practices (Roth \& Tobin, 2004) within this theoretical framework to 
further examine experiences from multiple angles. Co-generative dialogue is a "structured discussion between participants in educational situations, generally with a focus on improving practice" (Siry \& Zawatski, 2011, p. 346). Stith and Roth (2010) further suggest co-generative dialogue creates new awareness of classroom practices from multiple perspectives with the goal of providing greater learning opportunities. In conjunction with phenomenological theory, which focuses on the lived experiences of individuals and relies on first-source data (Moustakas, 1994; Patton, 1990), cogenerative dialogue allows the participants to have an equal voice in presenting their perceptions of a shared experience. The collection of first source data is also a chief concern of the phenomenological approach. The student-researcher was asked to bring in two different kinds of artifacts from the course: examples of assignments she found easy to navigate and accomplish, and examples of assignments she found difficult. Using these as the basis for our discussion, we talked about the course and the challenges therein. Through a careful and objective examination of the artifacts collected, themes emerged that help shed light on participants' lived experiences and they make meaning (Patton, 1990). We worked together to write our reflections from the conversation. In this article, the student words will be in italics.

\section{Participants}

Instructor: I am a new assistant professor at a major U.S. university located in the Southeast. I hold a master's degree in applied linguistics from an international university and a doctorate in school improvement from a different southeastern university. My primary teaching background includes English to Speakers of Other Languages (ESOL) in K12 settings as well as Intensive English Program (IEP) settings and other adult education situations. In addition, I have taught mainstream language arts, reading, and gifted education classes at the middle school level. I have taught graduate level ESOL education courses as an adjunct instructor for three years; this was my first year as assistant professor, and my first course taught in new position.

Student: I am an international student from China who received my master's degree in applied linguistics from a major 
university in China. I came to the U.S. to pursue a doctoral degree in an adult education program in the year 2012. I have learned English for more than 10 years, and have also studied Russian and French. English is a compulsory course for the College Entrance Exam as well as the National Postgraduate Entrance Exam.

\section{Assumptions}

Instructor: As the instructor, I made assumptions about the course, course participants, and assignments. First, I assumed that all students would be native speakers and currently certified, practicing classroom teachers. After meeting students and knowing some of them were non-native English speakers (NNES), I still assumed that their English would be such a high level that their NNES status would be a non-issue. Furthermore, I assumed that the kinds of assignments I like to provide (student generated discussions, group and pair work, technology-based, arts-based, etc.) are common experiences for all students. Finally, I assumed that students would easily and completely understand me and the assignments (including my methods of delivery, my rate of speaking, response time and clarity).

Student: I took the course because I am very interested in the ESL research, and my future research will still focus on this field. I have learned theories for SLA as well as different teaching approaches and methods. So I was wondering is there any difference between what I learned in China and what will be presented in this course. Because of different background and perspective of teachers in different countries, I thought I could learn different ESL teaching in American university setting. I assumed this course Teaching English to Speakers of Other Languages would focus on how to teach adult ELLs, not just K-12 learner and that maybe we would talk about how to teach ESL from linguistic perspectives.

\section{DATA COLLECTION AND ANALYSIS}

The student participant brought in two artifacts from class that exemplified assignments that she found easy and two that she found difficult. Using these assignment documents, we started a discussion about her experience of accessing the information necessary to be 
successful in the course, and my experience of attempting to provide that access. I asked three main questions to spur the conversation:

a) Describe this assignment. What was the task? What was the assignment's objective?

b) What made this assignment easy/difficult?

c) What strategies did you use to understand and complete the assignment?

The main points of data were the four collected artifacts and the notes taken during the conversation. From these notes, both participants wrote reflections based on their understandings of the conversation, highlighting key elements from each perspective. Each read the others' work and clarified any misunderstandings and further elaborated on points that seemed unclear. This phenomenological approach allowed us to look at the artifacts with no preconceived ideas and experience the assignments from another point of view.

\section{RESULTS}

Easy Artifact 1: Developing Language Objectives Activity - Written Assignment

In this activity, students were asked to choose a set of standards from content area and grade level of interest and develop language objectives related to key vocabulary, language functions, language skills, grammar or language structures, lesson tasks, and language learning strategies. Students were given an in-class, whole group practice set and shown models of what would constitute effective language objectives. The handout explicitly gave instructions and examples for each type of objective required. According to the student participant, the professor modeling, explaining, and providing examples were part of her feelings of ease with this assignment. In addition, she mentioned that since it was a writing assignment, she felt comfortable because she would have time to go over her work. Finally, she expressed comfort with the assignment since she had a lot of experience with not only learning English, but also studying it as an academic discipline. 
Easy Artifact 2: Program Model Evaluation: Group Jigsaw, Notetaking and Discussion

This activity allowed students to learn about various program models in a small group format. Students were assigned a small group in which to read and become an expert in one program model. A graphic organizer with prompts was utilized to help all students organize the pertinent information and prepare themselves as an expert. Class time was allotted to discuss the assignment with group members and organize the plan for reading the material and sharing notes. It was explained to students that the next week they would share their expertise with other members of the class in small group discussion format. They would be expected to share knowledge and understanding, evaluate the various models, and apply evaluations to determine which program model would best suit an educational situation. The student-researcher noted that this was an easy assignment because she was given class time to talk over the details of the assignment and clarify the learning outcomes with her classmates and professor. She values the time given to speak to and learn from her classmates. In addition, she felt that having the textbook to refer to for taking notes was helpful. She also noted that having a week to prepare gave her time to read ahead on her classmates' program models and have an idea of the material they would be presenting.

\section{Difficult Artifact 1: Strategy Lesson Presentation}

For this assignment, students were given a list of effective strategies for working with ELLs in the classroom. They each chose a different strategy to prepare a short lesson in a content area topic that highlighted the use of the strategy. Some of the preparation aspects of this assignment that made it challenging for the student participant included lack of background knowledge about the various strategies, lack of background knowledge about content area standards, new terminology that arose during the preparation of a content area lesson. In addition to these challenges, even though the student participant spent time before the presentation thinking about and planning the language she would need to present this lesson in English, she found trying to teach the lesson as a spontaneous act difficult. In particular, she noted that her communication of directions for activities did not 
produce the expected results in her students. She found it challenging to focus on her students' responses while simultaneously focusing on her own linguistic output. In particular, she felt her own personal creativity as a teacher was reduced and she was not able to show all that she understood about what would make an effective lesson.

\section{Difficult Artifact 2: Assumption about ELL Public Service Announcement}

This was the first assignment of the course and it was given out at the end of the first evening of class. Students were asked to read a short collection of assumptions about ELLs and information that detailed the information and misinformation about the origins of that assumption. Their job was to choose one of interest and create a public service announcement that would help dispel misunderstandings about ELLs. It was assigned as an individual activity and no examples or written instructions were provided. Since this was the first assignment of the course and she did not know her classmates or the professor well, the student participant found the individual nature of the assignment challenging. In addition, this was the first time she had ever been assigned a poster creation activity for an academic assignment, so the format for showing her understanding was incongruent with her other educational experiences. She found the concept of 'assumption' difficult, along with the evidence she was given to read about the assumption. In some cases, she felt that the evidence supported the assumption and so it made the objective of the assignment difficult to determine. Furthermore, the fact that no written directions or examples were given at the time the activity was disseminated added to her challenges. Finally, when other students presented their assumptions, she had trouble understanding them since she had not had time to read ahead and plan for listening to their presentations.

\section{DISCUSSION AND CONCLUSIONS}

Some key understandings about the experiences of teaching ELLs and learning at the graduate level in a university setting were revealed from this study. As a result of our discussion and reflections, some key suggestions for both instructors and students can be made. 


\section{Suggestions for Instructors}

Know your students' language levels. Instructors need to remain aware of ELLs' language proficiency and academic background and modify speech rate and pronunciation appropriately. ELLs in graduate level courses do have acceptable English test scores to gain admittance, yet it is important to keep in mind that their English skills are not the equivalent of native speakers of English and assuming this can create a difficult learning environment for these very motivated students. One strategy that would be helpful is providing lecture notes or PowerPoints of information necessary ahead of time for student access. Prior knowledge of lecture material increases ELLs' abilities to comprehend the spoken lecture and participate at deeper levels in spontaneous class discussions. This includes in-class discussion questions, activities, and assignments. While not every discussion or learning experience can be planned out, to the extent possible providing discussion prompts and directions for assignments early allows ELLs to prepare to a fuller extent and feel more confident in class.

Provide opportunities for interaction. Instructors should encourage and provide opportunities for interactions, and organize various group-work activities. However, it is important to consider the affective factors of group work when pairing ELLs with uncooperative or passive native speakers and set up opportunities for real language interaction to take place that is respectful to both parties (Daoud, 2003). One strategy that is helpful is to stop after explaining an activity and give students a few minutes to talk to each other about the assignment criteria and due dates prior to either moving on or dismissing class.

Pay attention to patterns of language use in the classroom. Instructors should try to increase awareness of their own language use and pay special attention to language used in the classroom. Further, they should observe classroom dynamics and take the perspective of an outsider occasionally in order to better understand what non-native English speakers might be experiencing. It will help teachers to see "what they have taken for granted and assumed that ELLs already 
know" (Cho \& Reich, 2008, p. 239). The graduate level university classroom is a dynamic space embedded with culturally influenced actions and speech. Without conscious attention by the instructor to ways that language is used and received, many ELLs struggle to attain academic standing to the level of their native English-speaking peers.

\section{Suggestions for Students}

Be visible to the instructor. Make yourself known to the instructor; ask for what you need. Students should make full use of all opportunities to interact with the instructor to clarify the course requirement, assignment, and any subject matter they cannot understand. If they cannot catch up with speech rate of the instructor, they should let the instructor know.

Initiate relationships with classmates. Meet your classmates, both native English speakers and other ELLs. Student in this conversation did benefit a lot from peers. Many native English speakers are very willing to help ELLs to clarify assignment requirement, cultural terms and provide effective feedbacks. Student in this conversation comes from China. As she knows, many Chinese students prefer staying together in classroom, discussing and making presentation together. It did help them to share feelings about challenges or problems they meet, but it also makes them lose many opportunities to communicate with native English speakers. ELLs should interact with various cultures throughout the course. They should speak out more often with native speakers to practice their speaking, listening as well as learn more cultural things to enhance mutual understanding with domestic students. Establish a good relationship with native speakers help ELLs to gain a sense of belonging, and promote social and academic integration successfully.

Prepare prior to class. Students should make full preparations ahead of time for class. To preview lecture notes, PowerPoints, or handouts is very helpful to have a better understanding of the class. At least, students can have a general idea of what will be presented in class. Besides, ELLs can check new words meaning using dictionary or translators. If ELLs can prepare 
well they feel more confident in class. It helps them to achieve academic goals.

Adjustment to a different academic environment, cultural differences and language proficiency are three important considerations for high level ELLs in the university setting. With limited academic curricula or special assistance available for ELLs once they have entered the mainstream university classroom, these students are challenged by language difficulties and lack of background knowledge. Thus, a supportive university environment is needed to help ELLs overcome challenges.

ELLs should have full access to appropriate curricula taught by qualified teachers using appropriate instructional resources and methods that match students' language and grade level. However, not many schools can afford such support (e.g., bilingual instructional materials, time, and specific guidelines). (Cho \& Reich, 2008, p. 238)

Psychological challenges, sense of belonging, and interactions with peers and professors all play a role in influencing ELLs' social integration and academic success. Utilizing these practical strategies can help ELLs overcome linguistic challenges and achieve academic goals.

\section{IMPLICATIONS}

The international student population continues to grow, and while graduate schools have typically seen larger enrollment numbers, since 2011, undergraduate student enrollment has exceeded graduate student enrollment in U.S. schools (Institute of International Education, 2014). It is not a coincidence that these numbers align with recruitment trends (Redden, 2014). International students are a lucrative, academically attractive market. However, it does a university little good to attract these students and not consider their academic needs as English language learners. Enrollment does not ensure graduation, and many academic transactions must take place to ensure all students have the best possible chance of attaining their educational goals. Of course many, if not most, of the responsibilities 
for learning justly fall to the learner. Nevertheless, as this study suggests, it is the responsibility of both the student and the instructor to be partners in learning. Pedagogical adjustments and considerations made by those who instruct ELLs can ensure positive student outcomes. Continued research into instructor beliefs and pedagogical practices is warranted.

\section{REFERENCES}

Bonazzo, C., \& Wong, Y. J. (2007). Japanese international female students' experience of discrimination, prejudice, and stereotypes. College Student Journal, 41(3), 631- 639.

Bifuh-Ambe, E. (2011). Postsecondary learning: Recognizing the needs of English Language Learners in mainstream university classroom. Multicultural Education, Spring, 13-19.

Biggs, J. (2003). Teaching for quality learning at university (2 ${ }^{\text {nd }}$ ed.). Buckingham: SRHE/Open University.

Buckridge, M., \& Guest, R. (2007). A conversation about pedagogical responses to increased diversity in university classrooms. Higher Education Research and Development, 26(2), 133146.

Cho, S., \& Reich, G. A. (2008). New immigrants, new challenges: High school social studies teachers and English language learner instruction. The Social Studies, 99(6), 235-242.

Daoud, A.M. (2003).The ESL kids are over there: Opportunities for social interactions between immigrant Latino and white high school students. Journal of Hispanic Higher Education, 2(3), 292-314.

Dornyei, Z., \& Scott, M. L. (1997). Communication strategies in second language: Definitions and taxonomies. Language Learning, 47, 171-210.

Ehrman, M., Leaver, B., \& Oxford, R. (2003). A brief overview of individual differences in second language learning. System, 31, 313-330.

Engle, J. \& Lynch, M. (2009). Charting a necessary path: The baseline report of public higher education systems in the access to success initiative. The Education Trust. ERIC 
Document 507873. Retrieved from

http://www.eric.ed.gov/PDFS/ED507873.pdf.

Hsieh, M. (2007). Challenges for international students in higher education: one student's narrated story of invisibility and struggle. College Student Journal, 41(2), 379-391.

Institute of International Education (2013). Open Doors 2014 "Fast Facts". Retrieved from http://www.iie.org/Research-andPublications/Open-Doors

Kanno, Y., \& Cromley, J. (2013). English language learners' access to and attainment in postsecondary education. TESOL Quarterly, 47(1), 89-121.

Kwon, Y. (2009). Factors affecting international students' transition to higher education institutions in the United States - From the perspective of office of international students. College Student Journal, 43(4), 1020-1036.

Lin, S., \& Scherz, S. (2014). Challenges facing Asian international graduate students in the US: Pedagogical considerations in higher education. Journal of International Students, 4(1), 1633.

Marambe, K. N., Vermunt, J. D., \& Boshuizen, H. P. A. (2012). A cross-cultural comparison of student learning patterns in higher education. Higher Education, 64, 299-316.

Moustakas, C. (1994). Phenomenological research methods. Thousand Oaks, CA: Sage.

Oxford, R. (1989a). Use of language learning strategies: A synthesis of studies with implications for strategy training. System, 17, $1-13$.

Oxford, R. (1989b). Language learning strategies: What every teacher should know. New York: Newbury House/Harper \& Row.

Parks, S., \& Raymond, P. (2004). Strategy use by nonnative-Englishspeaking students in an MBA program: Not business as usual! The Modern Language Journal, 88(iii), 374-379.

Patton, M. Q. (1990). Qualitative evaluation and research methods (2nd ed.). Thousand Oaks, CA: Sage.

Redden, E. (2014). Bridge or back door? Inside Higher Ed. Retrieved from https://www.insidehighered.com/news/2014/04/30/look- 
landscape-pathway-programs-international-students-runcooperation-profit

Rubin, J. (1975). What the "good language learner" can teach us. TESOL Quarterly, 9, 4-51.

Siry, A., \& Zawatski, E. (2011). 'Working with' as a methodological stance: Collaborating with students in teaching, writing, and research. International Journal of Qualitative Studies in Education, 24(3), 343-361.

Stith, I., \& Roth, W. (2010). Teaching as mediation: The cogenerative dialogue and ethical understandings. Teaching and Teacher Education, 26, 363-370. doi: $10.1016 /$ j.tate.2009.09.008

Valdez, G. (2015). U.S. higher education classroom experiences of undergraduate Chinese international students. Journal of International Students, 5(2), 188-200.

Wang, P., \& Machado, C. (2015). Meeting the needs of Chinese English language learners at writing centers in America: A proposed culturally responsive model. Journal of International Students, 5(2), 143-160.

Walpole, M. (2007). Economically and educationally challenged students in higher education: Access to outcomes. ASHE Higher Education Report, 33(3), 1-113.

JAMIE HARRISON, EdD, is assistant professor of ESOL Education.. Her research interests include issues of access for English learners, implicit teacher beliefs, and advocacy. Email: jlh0069@auburn.edu

HONG SHI, PhD, is a doctoral candidate of Adult Education. Her research interests include issues of learning styles of English learners, language learners' self-efficacy, and goal orientation. Email: hzs0032@auburn.edu

Manuscript submitted: November 5, 2015 Manuscript Revised: January 4, 2016 Accepted for publication: March 5, 2016 